\title{
ASSESSMENT OF CYCLIC TRIAXIAL BEHAVIOR OF SHIWALIK SANDSTONE
}

\author{
Sana Zafar' ${ }^{1}$ K.S.Rao ${ }^{2}$ \\ ${ }^{I}$ Assistant Professor (Adhoc), Civil Engg, Dept, M.M.M.U.T, Gorakhpur, U.P, India-273010 \\ ${ }^{2}$ Professor, Civil Engg, Dept, IIT Delhi, India-110016
}

\begin{abstract}
The mechanical properties of rock under dynamic conditions are of great importance in which the fatigue strength of rock plays a vital role. This study represents the effect of variable frequency on dynamic properties of Shiwalik Sandstone. Shiwalik sandstone samples were collected from the powerhouse location of UJH Multipurpose Project, Jammu and Kashmir . "Prediction of fatigue life of Shiwalik Sandstone under varying frequency" was done by conducting Cyclic Load test in Uniaxial and Triaxial condition. Cyclic testing was done at three frequencies i.e. $1 \mathrm{~Hz}, 2 \mathrm{~Hz}$ and $3 \mathrm{~Hz}$ [2] and at two confining pressures of 5 and $7 \mathrm{MPa}$ [6]. The $\mathrm{S}-\mathrm{N}$ curve [4] were plotted at different frequencies in uniaxial condition as well as in triaxial condition to explain the fatigue behaviour of soft rock (Shiwalik Sandstone) It has been observed that loading frequency as well as confining pressure has a significant effect on the fatigue life of the rock. As the frequency increases from $1 \mathrm{~Hz}$ to $3 \mathrm{~Hz}$ the fatigue stress increases. And in triaxial condition as the confinement increases from $5 \mathrm{MPa}$ to $7 \mathrm{MPa}$ the number of cycles at failure increases.
\end{abstract}

Keywords: Fatigue life, Shiwalik sandstone, Cyclic load test, Amplitude, Frequency, Base load, Waveform - ***

\section{INTRODUCTION}

The mechanical behavior of rock subjected to cyclic loading is important for rock engineering design and construction like drilling and blasting, underground openings, support assessment, resource and waste deposition, working of big machineries, explosions, earthquakes pavements etc. Cyclic loading causes deterioration of rock strength which leads to fatigue failure of rocks and this type of loading causes the failure of the underground structures at a lower fatigue strength. Deterioration of rock under cyclic loading is termed as Rock Fatigue. The maximum applied stress at which rock can withstand an infinite number of cycles without destruction is termed as Fatigue Stress. The stress level at which the failure takes place is Fatigue Strength and the number of cycles is known as Fatigue life of a rock. [7]

Fatigue properties of geologic materials are highly dependent on the rock type and the parameters of the cyclic loading like loading frequency, amplitude etc. [1-2] So the designer of a dynamically loaded structure must have adequate knowledge of the cyclic loading to design a stable structure against fatigue failure. Knowledge of fatigue characteristics could also help the designer to predict the fatigue behavior of the structure and take preventive measures. So proper attention should be focused on the dynamic properties of rocks with the goal of understanding their dynamic mechanical features under different loading conditions.

The objective of the study is to analyse the effect of frequency on dynamic properties of Shiwalik Sandstone in cyclic uniaxial loading condition and to study the effect of confining pressure on dynamic properties of Shiwalik Sandstone in cyclic triaxial condition

\section{EQUIPMENT AND TEST SCHEME}

\subsection{Rock Samples}

The present work deals with laboratory investigation of geotechnical properties and parameters of 'Shiwalik Sandstone'. The samples have been collected from the powerhouse location of UJH Multipurpose Project, Jammu and Kashmir (Fig.1)
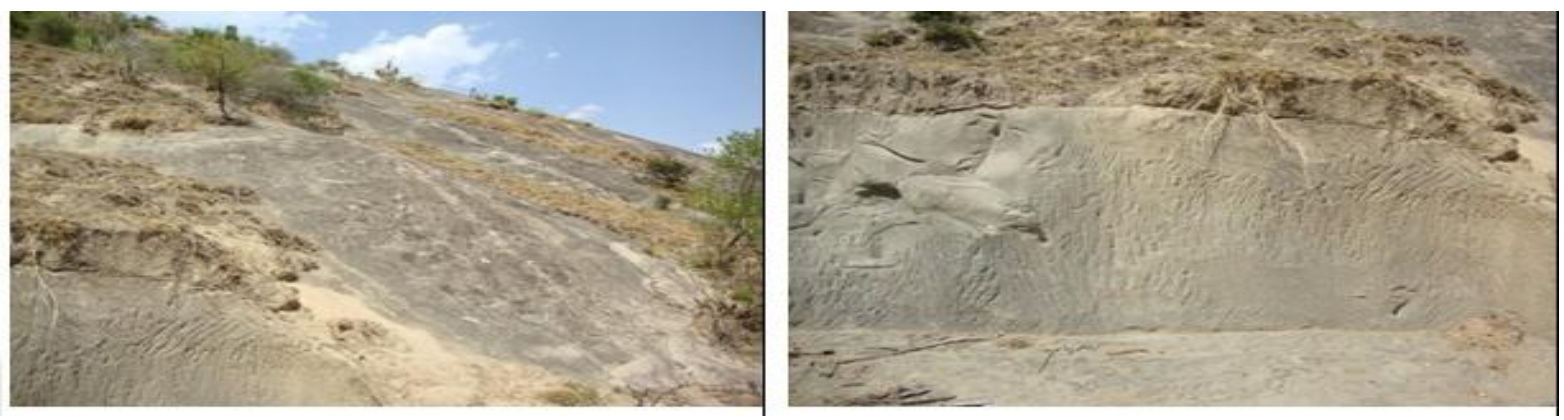

Fig. 1: Location of samples collection (at Powerhouse, UJH Multipurpose Project, J\&K) 
Regionally the project area forms a part of the tertiary belt of outer Himalaya occupied by rocks belonging to Murree Group, Lower Shiwalik, Middle Shiwalik and Upper Shiwalik Groups from north to south. The present source of samples i.e., powerhouse is located in the medium to coarse grained sand stone with thin clay layers of Middle Shiwalik Group. The general strike of rock units $\mathrm{N} 65^{\circ} \mathrm{W}-\mathrm{S} 65^{\circ} \mathrm{E}$ to $\mathrm{N} 75^{\circ} \mathrm{W}-\mathrm{S} 75^{\circ} \mathrm{E}$ and dip varying from $30^{\circ}$ to $45^{\circ}$ southerly. Its age lies between Lower Pliocene to Miocene. (Source: GSI)

The above site is chosen for the investigation because many of our projects like Hydropower plant etc. are going on in the foothills of Himalayas. These plants require different type of heavy machines which will generate cyclic loading. The samples were cut into 2:1 length to diameter ratio with an average diameter of $51 \mathrm{~mm}$. Samples were prepared as per ISRM standards[8]. The UCS value for the rock sample was obtained as $46 \mathrm{MPa}$.

\subsection{Equipment}

The testing facility was based on the principle of "Closed Loop Servo Control". The system can be operated in load or displacement control mode.It Consists of three parts i.e. Compression Loading Frame (1000 KN), Power Pack Unit ,Control system and Control Software

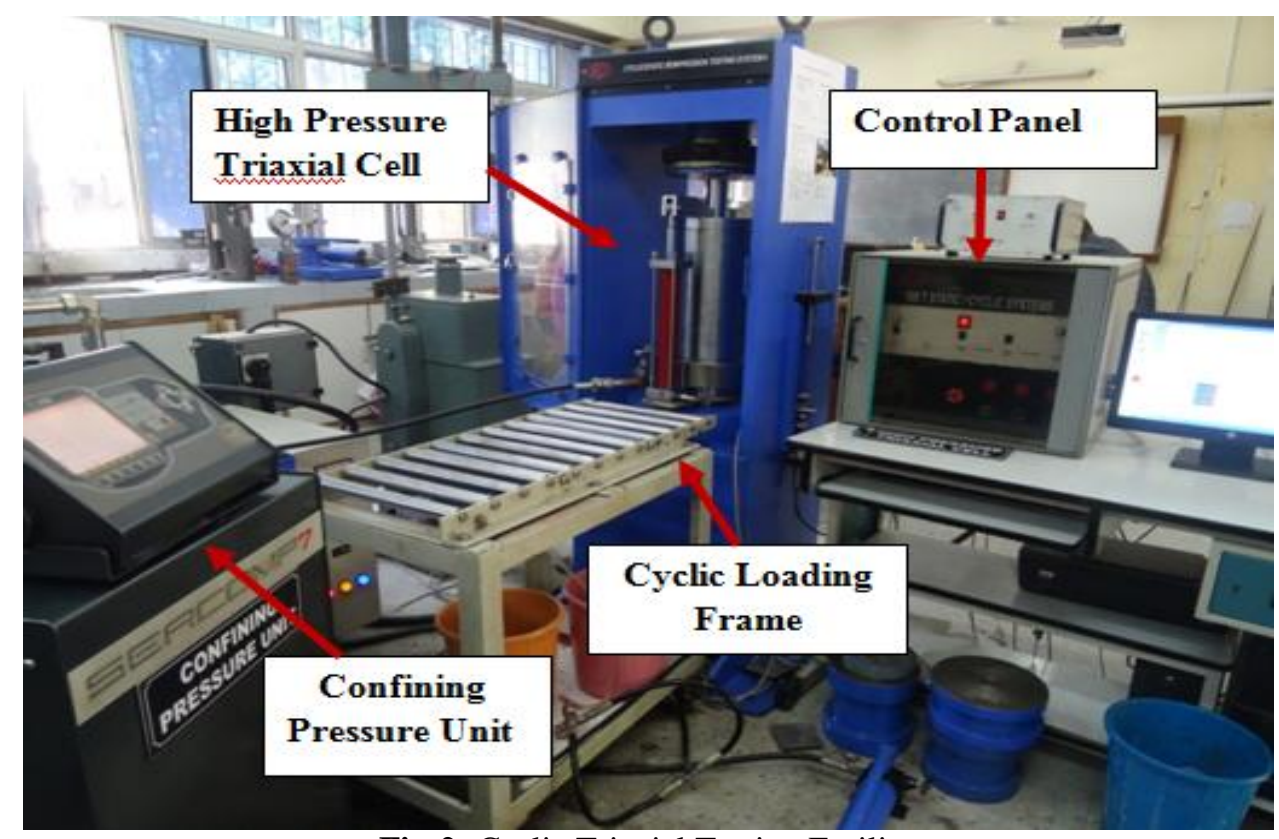

Fig-2: Cyclic Triaxial Testing Facility

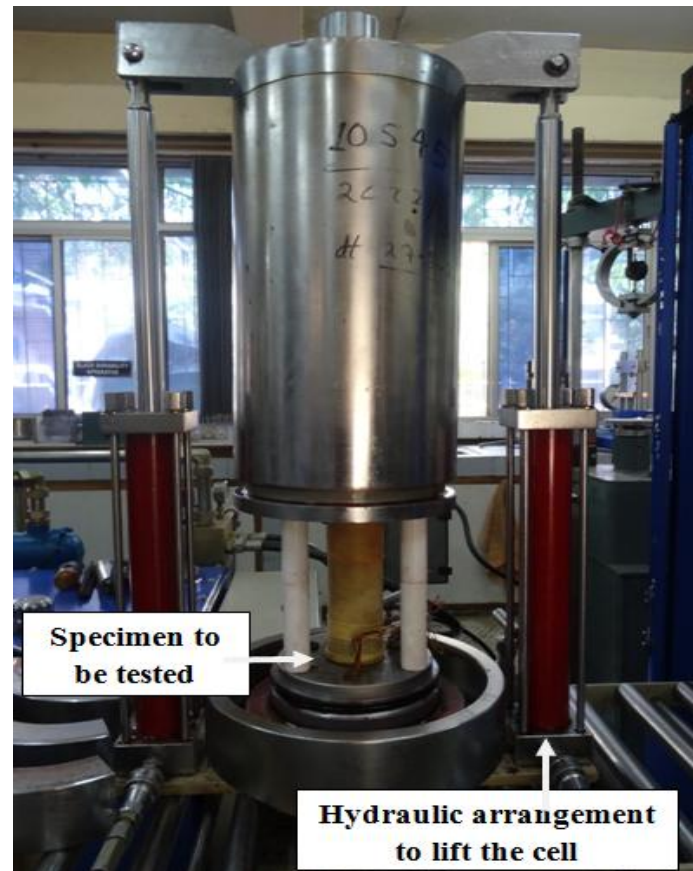

Fig-3: High Pressure Triaxial Cell 
The HPT cell can withstand confining pressure upto $140 \mathrm{MPa}$.It is basically designed for $\mathrm{N}_{\mathrm{X}}$ size sample. There is a hydraulic jack for the lifting of the cell so that samples can be easily placed and a valve which is released for the lowering of the cell.
The tests were conducted under strain controlled mode. In order to "Predict the Fatigue Life of Shiwalik Sandstone under Variable Frequency" cyclic test were carried out in Uniaxial [3] as well as in Triaxial State. The waveform used in cyclic compression test was sinusoidal.

\subsection{Test Scheme}

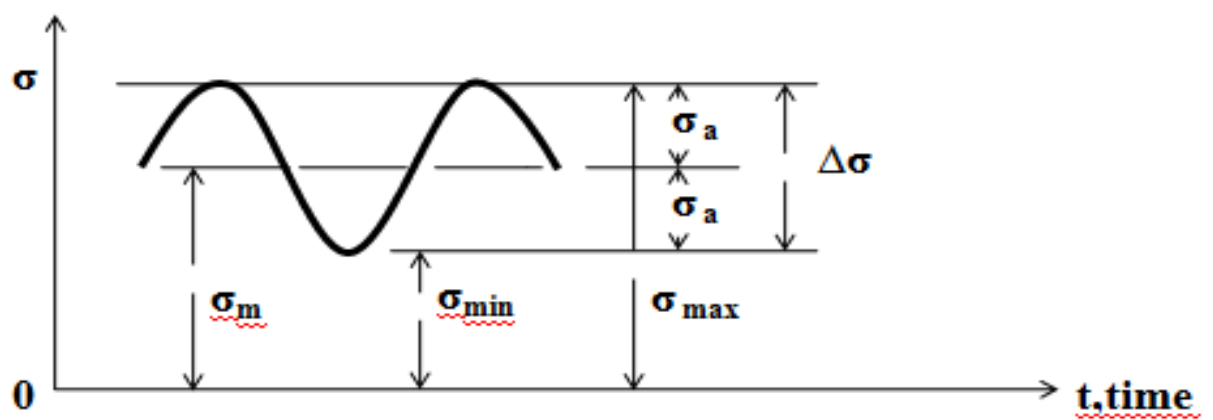

Fig-4: Sinusoidal waveform showing variation of stress with time ( $\sigma_{\mathrm{m}}$ is base load and $\sigma_{\mathrm{a}}$ is the amplitude)

\section{CYCLIC LOAD TEST}

\subsection{Uniaxial Cyclic Load Test at Varying}

\section{Frequency}

In the first set of experiment test were conducted to study the effect of frequency on fatigue strength of rock. So testing was done at frequency of $1 \mathrm{~Hz}, 2 \mathrm{~Hz}$ and $3 \mathrm{~Hz}$. The waveform used was sinusoidal.The valley stress was taken as $50 \%$ of UCS and peak stress varied from $90 \%$ to $60 \%$ of UCS. Four samples of $\mathrm{N}_{\mathrm{X}}$ size were tested at different values of peak stress at each frequency

Table-1: Observation of the Cyclic Load Test in Uniaxial codition at Varying Frequency

\begin{tabular}{|l|l|l|l|}
\hline $\mathrm{f}=1 \mathrm{~Hz}$ & $\mathbf{S}(\boldsymbol{\%} \mathbf{U C S})$ & Base $(\mathbf{k N})$ & $\mathbf{A m p}(\mathbf{k N})$ \\
\hline $\mathbf{N}$ & 90 & 45.15 & 36.12 \\
\hline 77 & 80 & 45.15 & 27.09 \\
\hline 146 & 70 & 45.15 & 18.06 \\
\hline 1400 & 60 & 45.15 & 9.03 \\
\hline 10000 & & \\
\hline
\end{tabular}

\begin{tabular}{|l|l|l|l|}
\hline $\mathrm{f}=2 \mathrm{~Hz}$ & \\
\hline $\mathbf{N}$ & $\mathbf{S}(\boldsymbol{\%} \mathbf{U C S})$ & Base $(\mathbf{k N})$ & $\mathbf{A m p}(\mathbf{k N})$ \\
\hline 113 & 90 & 45.15 & 36.12 \\
\hline 465 & 80 & 45.15 & 27.09 \\
\hline 913 & 75 & 45.15 & 22.57 \\
\hline 10000 & 70 & 45.15 & 18.06 \\
\hline
\end{tabular}

\begin{tabular}{|l|l|l|l|}
\hline $\mathrm{f}=3 \mathrm{~Hz}$ & \multicolumn{3}{|l|}{} \\
\hline $\mathbf{N}$ & $\mathbf{S}(\boldsymbol{\%} \mathbf{U C S})$ & Base $(\mathbf{k N})$ & Amp $(\mathbf{k N})$ \\
\hline 146 & 90 & 45.15 & 36.12 \\
\hline 327 & 85 & 45.15 & 31.60 \\
\hline 10000 & 80 & 45.15 & 27.09 \\
\hline
\end{tabular}

\subsection{Cyclic Triaxial Strength Test Under Varying}

\section{Confining Pressure}

Cyclic triaxial test was performed on Shiwalik Sandstone samples under two confining pressure of $5 \mathrm{MPa}$ and $7 \mathrm{MPa}$.
[6] The parameters of cyclic loading were same as that of cyclic uniaxial state. 
Table-2: Observation of the Cyclic Load Test in Triaxial codition at Varying Confining Pressure

\begin{tabular}{|c|c|c|c|c|}
\hline \multicolumn{5}{|c|}{$0 \mathrm{MPa} \sigma_{\mathrm{c}}=46 \mathrm{MPa}$} \\
\hline Sample Id & $\mathbf{N}$ & $\mathbf{S}(\% \mathbf{U C S})$ & Base $(\mathbf{k N})$ & $\operatorname{Amp}(k N)$ \\
\hline A12 & 77 & 90 & 45 & 36 \\
\hline $\mathrm{A} 21$ & 146 & 80 & 45 & 27 \\
\hline A 31 & 1400 & 70 & 45 & 18 \\
\hline A32 & 10000 & 60 & 45 & 9 \\
\hline \multicolumn{5}{|c|}{$5 \mathrm{MPa} \sigma_{1}=97.96 \mathrm{MPa}$} \\
\hline Sample Id & $\mathbf{N}$ & $\mathbf{S}(\% \mathbf{U C S})$ & Base $(\mathbf{k N})$ & $\operatorname{Amp}(\mathbf{k N})$ \\
\hline $\mathrm{S} 1$ & 690 & 90 & 96 & 77 \\
\hline $\mathrm{S} 2$ & 999 & 80 & 96 & 58 \\
\hline S3 & 1580 & 75 & 96 & 48 \\
\hline S4 & 10000 & 70 & 96 & 39 \\
\hline \multicolumn{5}{|c|}{$7 \mathrm{MPa} \sigma_{1}=166.56 \mathrm{MPa}$} \\
\hline Sample Id & $\mathbf{N}$ & $\mathrm{S}(\% \mathrm{UCS})$ & Base $(\mathbf{k N})$ & $\operatorname{Amp}(\mathbf{k N})$ \\
\hline S5 & 1124 & 90 & 163 & 131 \\
\hline S6 & 2567 & 85 & 163 & 115 \\
\hline S7 & 3464 & 80 & 163 & 99 \\
\hline S8 & 10000 & 75 & 163 & 82 \\
\hline
\end{tabular}

\section{EXPERIMENTAL RESULTS AND DISCUSSION}

In the first set of experiments test were conducted to study the effect of frequency on the cyclic fatigue behavior of

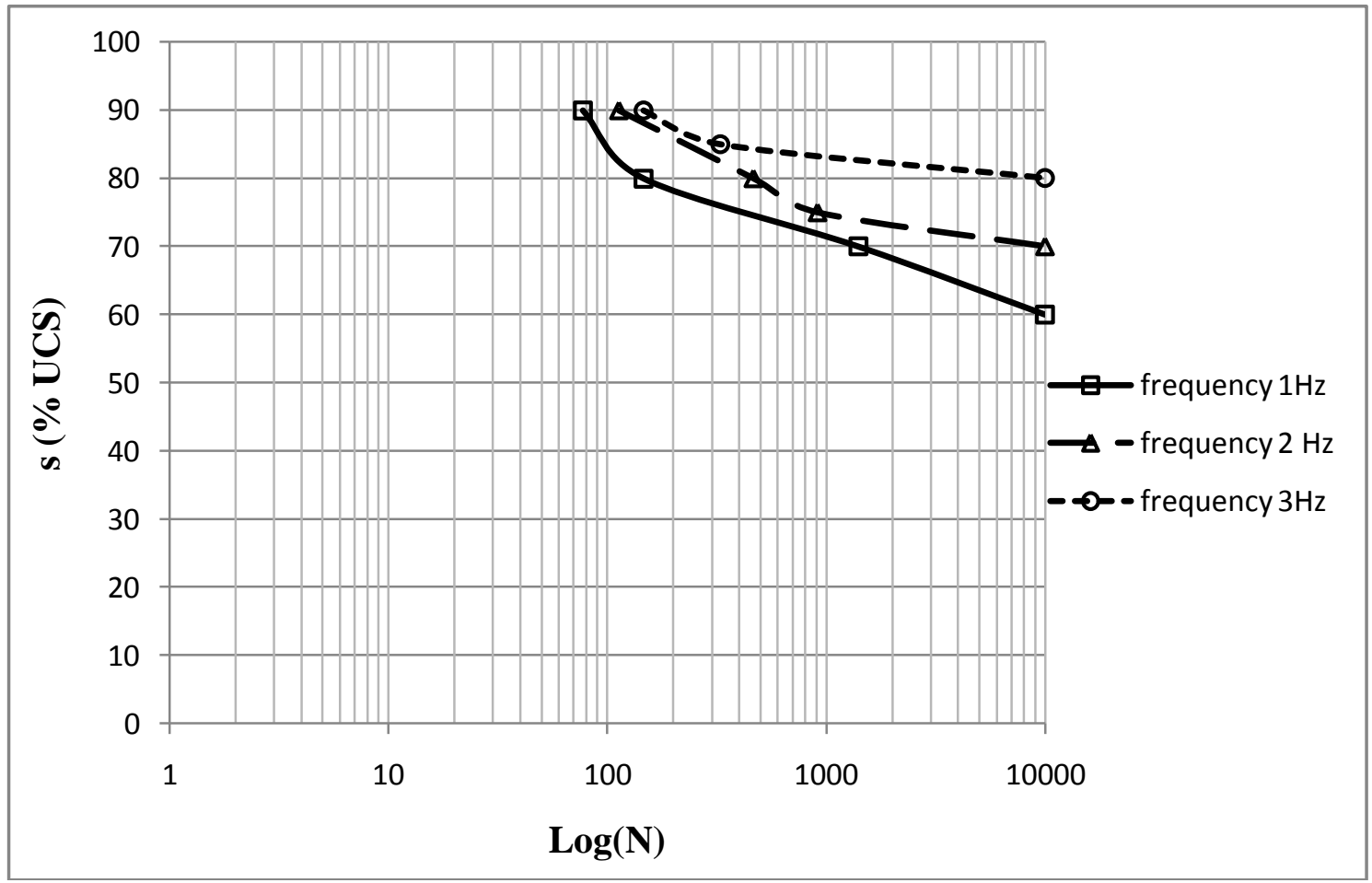

Fig-4:Comparison between S-N curve for Shiwalik Sandstone under varying frequency 
From the S-N curve it is clear that as the frequency increases the number of cycles at failure also increases.Fatigue strength of Shiwalik Sandstone goes on increasing as the frequency increases. Fatigue strength of Shiwalik Sandstone at $1 \mathrm{~Hz}$ frequency is $60 \%$ of UCS at $2 \mathrm{~Hz}$ it is $70 \%$ of UCS and at $3 \mathrm{~Hz}$ frequency it is $80 \%$ of UCS. This shows that as the frequency increases rock fatigue occurs at a higher stress and so the fatigue life of the rock increases.
When subjected to dynamic or cyclic loads, different materials respond in different ways.Some of these materials become stronger and more ductile, while others become weaker and more brittle In this case as the frequency is increasing the material is gaining strength. And so the S-N curve shifts up at higher frequency.

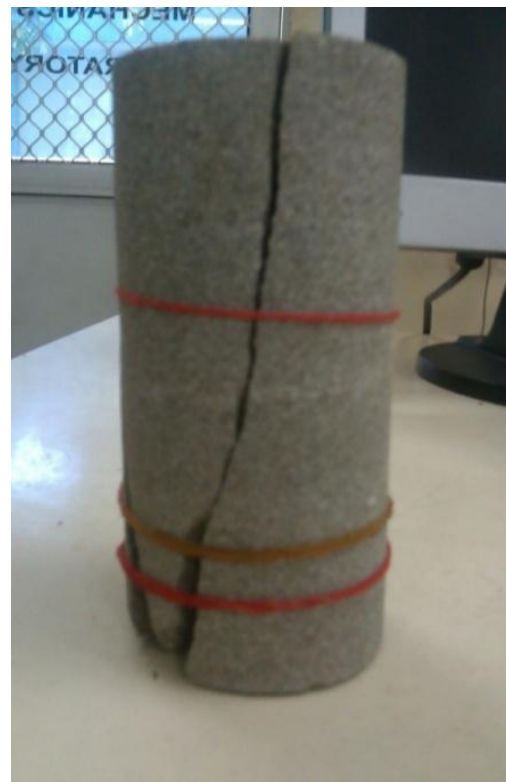

(a) $\mathbf{f}=1 \mathrm{~Hz}$

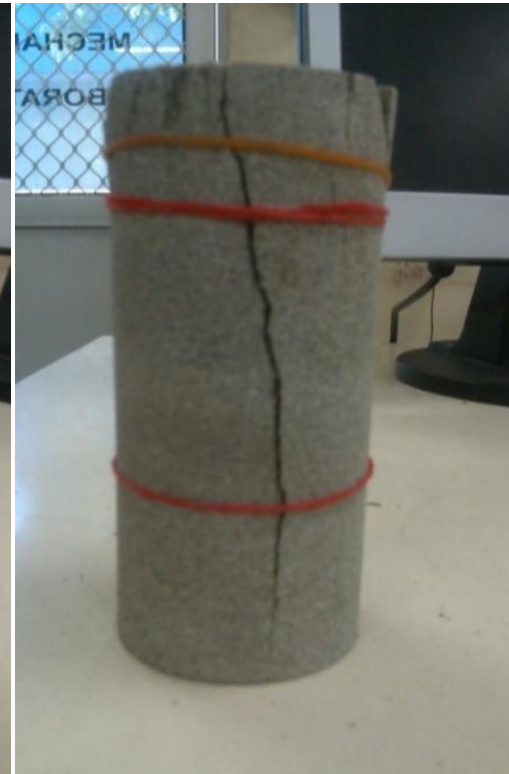

(b) $\mathbf{f}=\mathbf{2} \mathrm{Hz}$

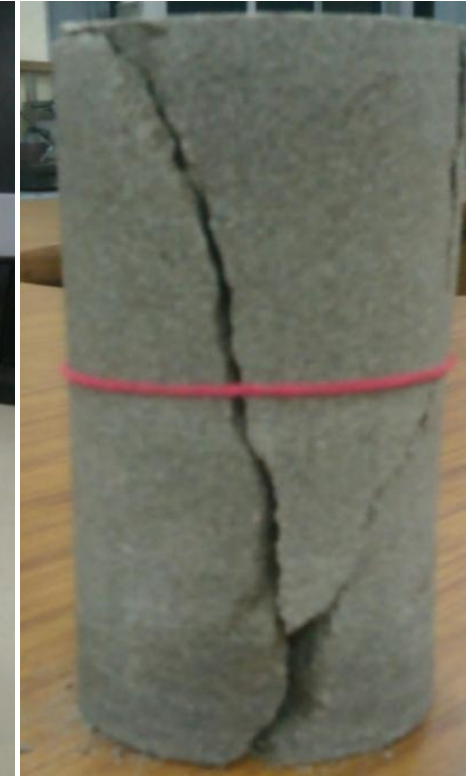

(c) $\mathbf{f}=\mathbf{3 ~ H z}$

Fig-5: Failed samples of Shiwalik Sandstone under Varying Frequency

In the second set of experiments test was conducted to study the effect of varying confining pressure on the fatigue strength of rock. The results are based on the S-N curve shown below.

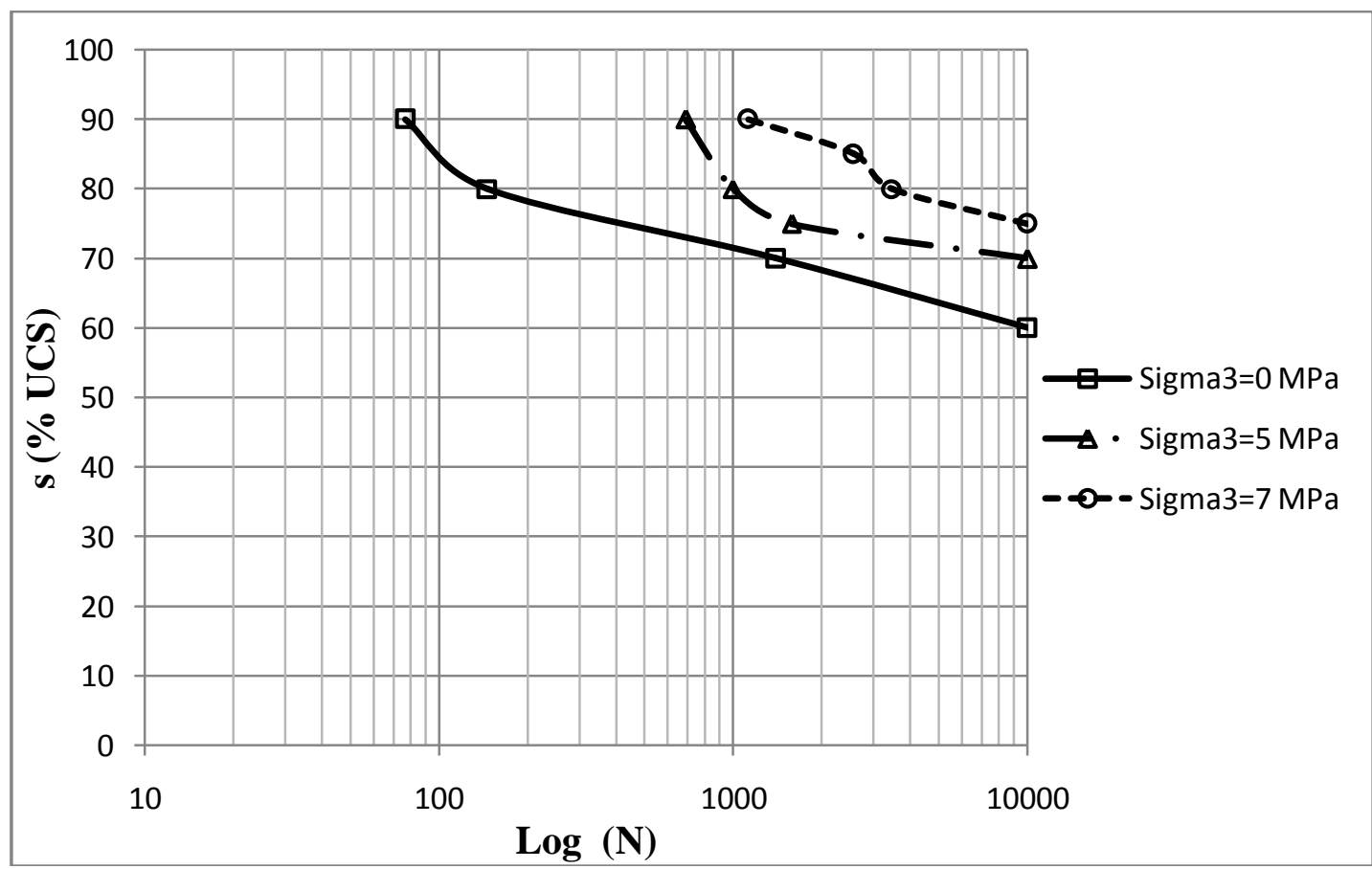

Fig-6:Comparison between S-N curve for Shiwalik Sandstone under varying Confining Pressure 
From the S-N curve it is clear that the fatigue life of the rock increases as the confinement increases. As the confinement increases the stiffness of the rock increases and so the strength also increases. Failure pattern for Shiwalik
Sandstone clearly shows that at same frequency the failure plane extends to the bottom in unconfined state and in confined state it is not so.

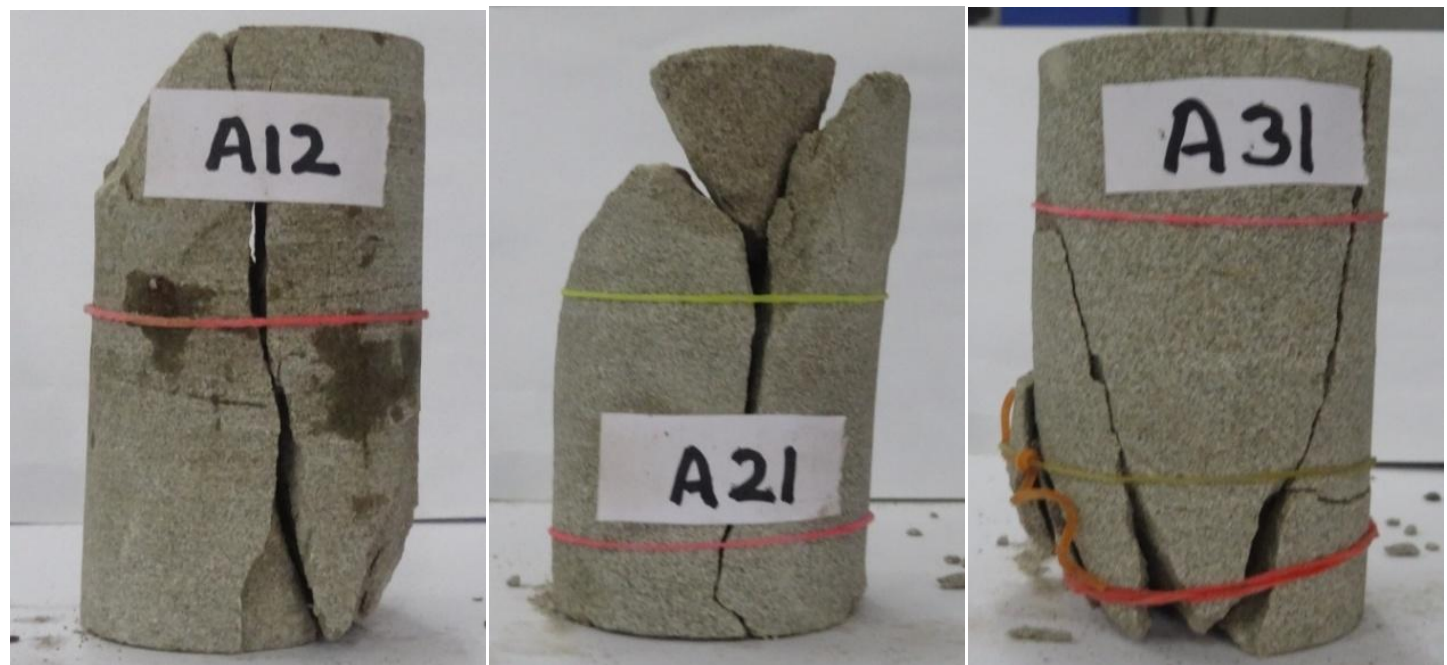

Fig-7: Failed samples in Cyclic Triaxial test at $\mathrm{f}=1 \mathrm{~Hz}$ and $\sigma_{3}=0$

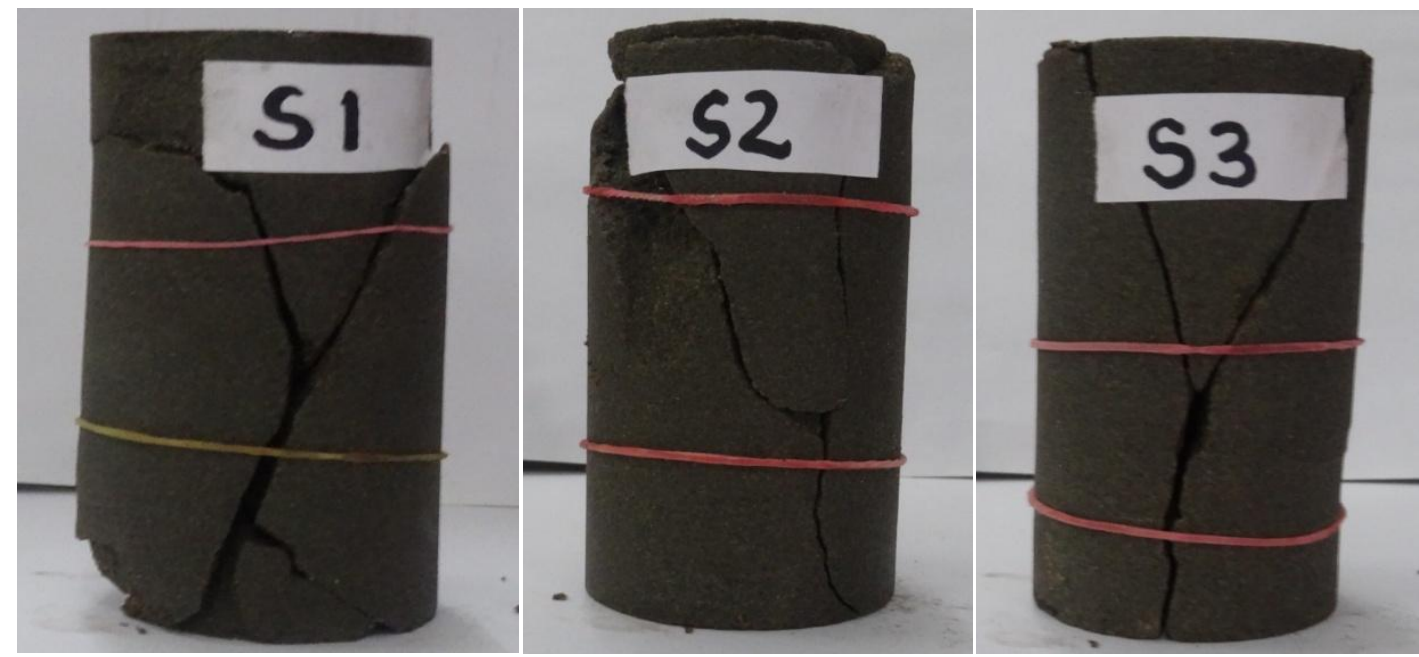

Fig-8: Failed samples in Cyclic Triaxial test at $\mathrm{f}=1 \mathrm{~Hz}$ and $\sigma_{3}=5 \mathrm{MPa}$

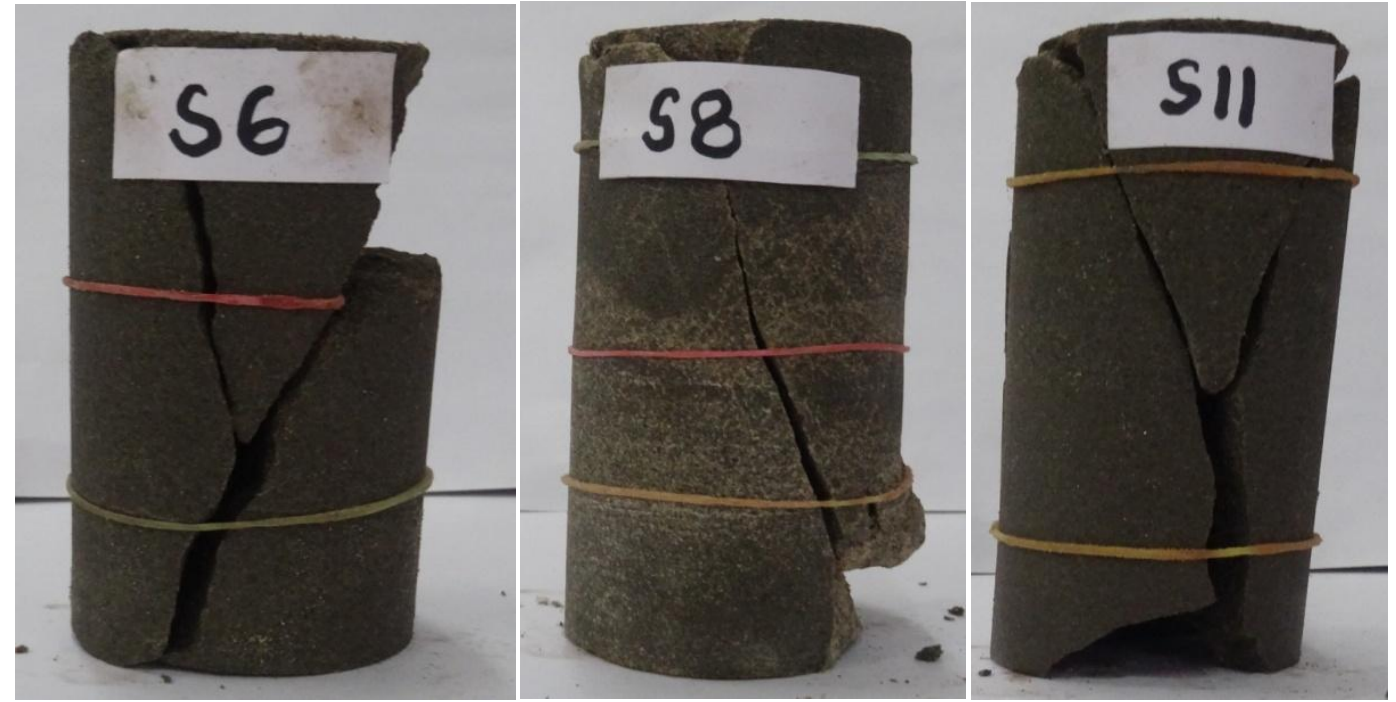

Fig-9: Failed samples in Cyclic Triaxial test at $\mathrm{f}=1 \mathrm{~Hz}$ and $\sigma_{3}=7 \mathrm{MPa}$ 


\section{CONCLUSION}

- $\quad$ Cyclic Uniaxial behaviour of Shiwalik Sandstone was studied and fatigue limit was obtained under varying frequency.S-N curve was plotted. [4]

- $\quad$ As the frequency of loading increases the number of cycles at failure increases which can be clearly observed from the $\mathrm{S}-\mathrm{N}$ curve at $1 \mathrm{~Hz}, 2 \mathrm{~Hz}$ and $3 \mathrm{~Hz}$ frequencies

- $\quad$ This study can also be useful for the performance of machine foundations which produce vibrations generally at a frequency of $1-5 \mathrm{~Hz}$.

- The failure pattern shows that larger the frequency wider is the localised failure band which is very much in agreement with the study done in 2012 [5]

- It has been found that as the confinement increases the voids reduce and material gains stiffness and strength and so the fatigue life of the rock increases. This is clearly visible by the S-N curve

\section{ACKNOWLEDGEMENTS}

The authors would like to express their deep gratitude towards Prof. K.G.Sharma, Civil Engineering Department, Indian Institute of Technology Delhi for his valuable guidance.They would also like to thanks the technicians of the Rock Mechanics Laboratory,IIT Delhi for their cooperation.

\section{REFERENCES}

[1]. Bagde M.N. and V. Petros,2005."Fatigue properties on intact sandstone samples subjected to dynamic uniaxial cyclical loading." International Journal of Rock Mechanics \& Mining Sciences 42, 237-250.

[2]. Bagde M.N.and Petros V.,2005."Waveform effect on fatigue properties of intact sandstone in uniaxial cyclical loading."'Rock Mechanics \& Rock Engineering 38,169-196.

[3]. Bagde, M.N., Petros, V., 2004. "The Effect of Machine Behaviour and MechanicalProperties of Intact Sandstone Under Static and Dynamic Uniaxial Cyclic Loading” Rock Mechanics \& Rock Engineering 37,3-23.

[4]. Burdine NT, 1963. "Rock failure under dynamic loading conditions."SPE J 3:1-8

[5]. Enlong Liu,Runqiu Huang, Siming He, 2012."Effects of frequency on the dynamic properties of intact rock samples subjected to cyclic loading under confining pressure conditions." Rock Mechanics \& Rock Engineering 45,89102.

[6]. EnLong Liu, Siming He, Xinhua Xue, Jin Xu "Dynamic Properties of Intact Rock Samples Subjected to Cyclic Loading under Confining Pressure Conditions" Rock Mechanics \& Rock Engineering

[7]. Vutukuri,V.S.,Lama,R.D. and Saluja,S.S. 1978 , "Handbook on mechanical properties of rocks (Series on rock and soil mechanics)." Trans Technical Publication,pp.279-289

[8] IS :9179-1979 "Method for preparation of rock specimen for laboratory testing"

\section{BIOGRAPHIES}

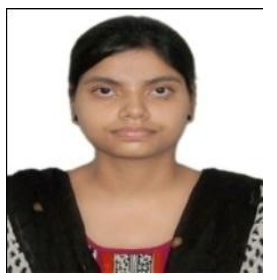

Sana Zafar ,is a Assistant Professor in Civil Engg. Department, Madan Mohan Malviya University of Technology Gorakhpur, U.P .India 273010 (e mail-zsanao6@gmail.com)

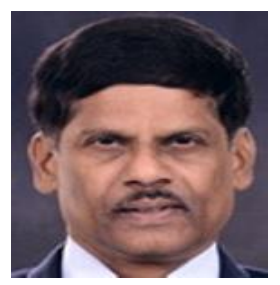

Dr. K.S. Rao is a Professor, Civil Engg. Department, IIT Delhi.-110016 ,India(e-mail-raoks@civil.iitd.ac.in) 